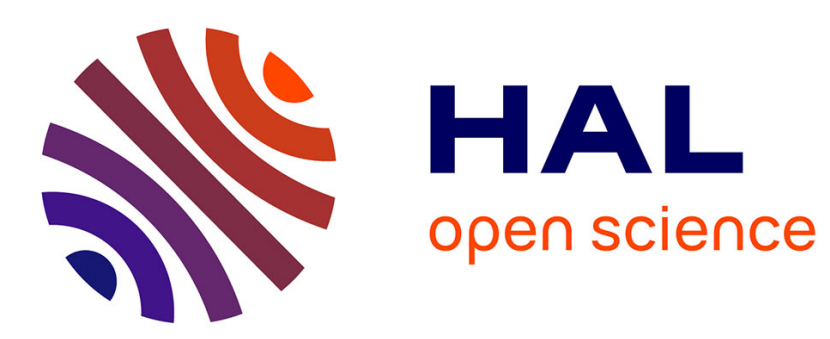

\title{
Between Deradicalisation and Disengagement: The Re-engagement of the Radical Actor?
}

\author{
Bartolomeo Conti
}

\section{To cite this version:}

Bartolomeo Conti. Between Deradicalisation and Disengagement: The Re-engagement of the Radical Actor?. Terrorism, Radicalisation \& Countering Violent Extremism: Practical Considerations \& Concerns, pp.43 - 56, 2019, 10.1007/978-981-13-1999-0_4. halshs-03089702

\section{HAL Id: halshs-03089702 \\ https://shs.hal.science/halshs-03089702}

Submitted on 13 Jan 2021

HAL is a multi-disciplinary open access archive for the deposit and dissemination of scientific research documents, whether they are published or not. The documents may come from teaching and research institutions in France or abroad, or from public or private research centers.
L'archive ouverte pluridisciplinaire HAL, est destinée au dépôt et à la diffusion de documents scientifiques de niveau recherche, publiés ou non, émanant des établissements d'enseignement et de recherche français ou étrangers, des laboratoires publics ou privés. 


\title{
Between Deradicalisation and Disengagement: the Re-engagement of the Radical Actor?

\author{
Bartolomeo Conti
}

\begin{abstract}
Based on his experience working as a sociologist in the field of violent extremism, Conti argues that the terms "disengagement" and "deradicalisation" are limited in their meaning, as they consider the radicalised person "as an actor with no legitimacy and without any genuine political commitment". Offering a new approach to reintegrating radicalised individuals into society, Conti describes a 2015 study which he conducted entitled engagements citoyens ("civic commitments") in which 12 inmates were interviewed and encouraged to speak about their struggles inside and outside of prison, while also speaking with prison staff and other members of society. The primary aims of this programme were to enable inmates to engage in conversation with individuals having different perspectives and to continue instructing them in light of what they revealed in the last phase of the programme, during which they spoke about themselves and described "personal hardship related to their backgrounds". Conti concludes that this programme revealed the necessity for inmates to be offered a safe space to verbalise their anger and feelings of injustice.
\end{abstract}

Keywords Integration $\bullet$ Disengagement $・$ Inmate $・$ Rehabilitation $\bullet$ Dialogue

B. Conti

Centre d' études des mouvements sociaux (CEMS)

Ecole des Hautes Etudes en Sciences Sociales, Paris, France

e-mail:bartolomeo.conti@ehess.fr 
In January 2015, the French prison administration charged a small team of sociologists to carry out an experimental action research in two French prisons with twin objectives: to update the tools for the identification of "radicalised" inmates and to come up with a programme, called "engagements citoyens" ("civic commitments"), that would deal with them in view of their reintegration into society. ${ }^{1}$ The research and engagement with radicalized individuals in the prison setting clearly showed that notions of "deradicalization" and "disengagement" were reductive and inappropriate: what emerged was the need to explore new concepts. Based on my experience as a sociologist involved in the study, I wish to offer an approach that does not exclude $a$ priori the legitimacy of commitment of the individual, but rather aims at supporting people in their efforts to re-define the modalities of their commitment. This is achieved through a reflection on the causes leading to break away with society and embrace violence and, among other factors, by abandoning the process of dehumanisation of the other which is the prelude of terrorist violence. Based on an individual and collective work, this perspective seeks to "re-commit" the radical person, in keeping with the idea that commitment is the cornerstone of citizenship.

\section{DERADICALISATION AND DISENGAGEMENT}

The rehabilitation of radicalised individuals has become a key issue for governments and societies. It is of course a matter of public safety, but it may also be framed as a question of "public health": what we do with citizens that have chosen the path of ideological violence? How do we punish them and ensure that they will not threaten the safety of others? Beyond these security issues, other questions come to

\footnotetext{
${ }^{1}$ Generally speaking, action research uses theoretical knowledge in order to produces practical tools. Its aim is to reinforce the capacity of action of concerned people, helping them to develop methods and tools to ameliorate their practice, as well their position and attitude, though a thinking about themselves and their position in the society.

The action research project was carried out by Association Dialogues Citoyens (ADC), a non-profit organisation created by a small group of sociologists, who adapted the method of sociological intervention and applied it to young people at odds with society (juvenile delinquency, school drop-out, violence, etc.) in view of empowering and favouring individual rather than collective awareness. This action research was carried out in two French prisons, (Osny and Fleury_Merogis), where around 50 detainees took part in four programmes that lasted for a year (February 2015 - March 2016) with each programme involving around 12 inmates. This article is based mainly on the first program, which took place in Osny prison, where fifteen inmates took part for two months in a program called "citizen commitments". The theoretical framework of this approach exposed in this article is were inspired also by similar initiatives implemented in others contexts that were not necessarily related to radicalisation.
} 
light: how do we help them re-establish social connections, even family links, or in other words reintegrate them into society? Such points are of particular interest as prison has been shown not to be the best venue to make making extremists renounce violence; on the contrary, a prison stay has sometimes strengthened their determination to commit acts of terrorism. ${ }^{2}$ The fact that democratic countries' systems of criminal law prevents the authorities from detaining people for an indefinite period of time also adds to the urgency of the issue. Radicalised individuals or those convicted for terrorism are generally meant to be released, whatever their level of radicalisation. The final, and even more complex question is this: should young people who joined organisations such as the so-called Islamic State in Iraq and Syria (ISIS), some of them underaged, be treated like victims, similar to individuals brainwashed by a sect? If they are indeed victims, their reintegration into society through rehabilitation is not a mere possibility, but above all an obligation of societies. ${ }^{3}$

During the last two decades, many countries have thus experimented with programmes usually referred to as "deradicalisation". These programmes - most of which have yet to be evaluated definitively - usually involve a large variety of actors (psychologists, imams, political analysts, social assistants, etc.), and rely on varied and sometimes conflicting methods. This diversity is a reflection of multiple interpretations of the causes of radicalisation. The very notion of "radicalisation" is open to a plurality of meanings. These multiple meanings are difficult to grasp, not least because actors do not speak about the same phenomenon. As Sedgwick notes, ${ }^{4}$ radicalisation eventually ends up being a "source of confusion" rather than a source of understanding and

\footnotetext{
${ }^{2}$ Cfr. Farhad Khosrokhavar, Prisons de France : Violence, radicalisation, deshumanisation. Surveillants et détenus parlent, Robert Laffont, 2016.

${ }^{3}$ A main divergence between countries, and also between initiatives implemented in the same country, is related to the balance between the need for security and the social reinsertion of the radicalized person. It becomes more and more clear, but also politically controversial, that if "deradicalisation" aims at getting the person out from ideological violence through its reinsertion into society, the political and social answer cannot just done according to security.

${ }^{4}$ Sedgwick Mark, 2010, «The Concept of Radicalization as a Source of Confusion », Terrorism and Political Violence, 22 :4: 479-494.
} 
explanation. ${ }^{5}$ The notion of "deradicalisation" is in turn even more uncertain and covers different meanings and programmes, as Alex Schmid has shown in a seminal study. ${ }^{6}$

According to a broad definition of deradicalisation given by John Horgan, these programmes "are generally targeted at individuals who have become radical with the aim of reintegrating them into society or at least dissuading them from violence", ${ }^{, 7}$ Alex Schmid stated that "de-radicalisation efforts are generally of two types: (i) individual ideological de-radicalisation, using psychological and religious counselling to produce a change of mind, and (ii) collective de-radicalisation, using political negotiations to obtain a type of change of behaviour (e.g. cease fire, de-commissioning of arms)"» Regarding individual deradicalisation efforts, we can distinguish between the two different notions: "deradicalisation" and "disengagement". The first notion refers primarily to a cognitive rejection of certain values, attitudes and views - in other words, a change of mind, while the second notion refers to behavioral distancing from the violent terrorist modus operandi, in other words the renunciation of violence, without necessarily abandon of radical ideas.

This chapter argues that both notions of "deradicalization" and "disengagement" have significant limitations, especially because they consider the radical or radicalised person as an actor with no legitimacy and without any genuine political commitment: essentially, a non-actor. "Deradicalising" means changing an individual's mindset because the latter is implicitly viewed as improper, while disengaging means that the individual's vision cannot be changed. Therefore, in the latter case, the focus should be maintained on turning the individual into a harmless person through the renunciation to violence, which is the precondition for his/her release. These two notions, and the operational approaches that follow, would suggest that the person is incapable of being a subject with a political will. They also reject any idea that the motives behind the person's commitment might be legitimate. Both

\footnotetext{
${ }^{5}$ Farhad Khorsrokhavar defined radicalisation as "the process through which an individual or a group adopts a form of violent action which is directly related to an extremist ideology of political, social or religious content, that questions the established political, social or cultural order », Farhad Khosrokhavar, Radicalisation, 2014: 7-8.

${ }^{6}$ Schmid A.P., 2013, Radicalisation, De-Radicalisation and Counter-Radicalisation, The Hague: ICCT -http://www.icct.nl/download/file/ICCT-Schmid-Radicalisation-De-Radicalisation-CounterRadicalisation-March-2013.pdf

7 Institute for Strategic Dialogue, Tackling Extremism: De-Radicalisation and Disengagement (Copenhagen: Conference Report, 8-9 May 2012): 1-2.

8 Schmid A.P., 2013, Radicalisation, De-Radicalisation and Counter-Radicalisation, The Hague: ICCT http://www.icct.nl/download/file/ICCT-Schmid-Radicalisation-De-Radicalisation-Counter-RadicalisationMarch-2013.pdf : 41 .
} 
notions are thus based on the complete illegitimacy of individual and collective commitment, and, consequently, they imply that there is no need to attempt to understand the reasons for the commitment of a person or a group that advocates violence in the name of a certain vision of the world.

\section{THE EXPERIMENTAL PROGRAMME IN FRENCH PRISONS}

The action research the present writer was involved in was the first of this kind in France. The research started just a few days after the Charlie Hebdo attack and, as two of the terrorists who committed the attack had spent time in jail, prison was coming to be seen as a central "breeding ground" of radicalisation. As prison staff was under heavy pressure to find solutions, the sociologists in charge of the research encountered full collaboration from all prison sectors, whereas, in general, prison remains closed to members of civil society or academics.

The action research started with a deep diagnosis of life in prison: the relations between detainees and prison staff, and an analysis of the methods used by the latter to identify Islamist radicalization. Prison staff appeared to be generally unable to detect radicalisation, first because there were lacking a common definition of radicalization, and second because prison sectors and disciplines used to work independently from each other (highlighted the importance of working collectively). As such, radicalisation was often confused with religious behaviours, political protest or anti-institutional attitudes. This was a source of discrimination, stigmatization and conflicting relationships in prison, which eventually resulted in further radicalisation. The first step of the action research was thus to deconstruct existing concepts and instruments, which turned out to be often inappropriate and inefficient.

\section{AN INTERDISCIPLINARY APPROACH}

An interdisciplinary approach was adopted based on the observation that it is difficult, if not impossible, to know if someone is radicalised without developing a close relationship with him. This approach relied on the premise that there is no single pathway to radicalisation but a multiplicity of factors that converge together in quite unpredictable ways. As field research projects and practical programmes have shown, processes of radicalisation are experienced in different ways. The very concept of 
"process" reflects the various degrees or levels of radicalisation involved. ${ }^{9}$ As people do not necessarily radicalise for the same reasons or in similar ways, the need to assess the degree and the type of radicalisation (profile) became - at least in theory - a precondition in order to assign each radicalized person to a pertinent program and/or establish individualised follow-up sessions towards rehabilitation.

Only interdisciplinary work involving experts and practitioners from a large variety of disciplines can facilitate a more individualized approach. Each expert or practitioner contributes to a more global vision of each inmate through its own knowledge and competences. A committee composed of all prison sectors management, wardens, school, medical staff, members of integration, probation and supervision services - was established with the goal of selecting a group of detainees radicalized or suspected to be radicalised. The large spectrum of points of view represented in the committee was used to produce accurate and case-by-case evaluations, which allowed in-depth knowledge of detainees' individual trajectories and brought out the multiple vulnerabilities or fragilities that have marked the trajectory of most of inmates: family (broken families, lack of parental authority, violence), institutional (deschooling and mistrust of any institution), legal (delinquent path, prison), geographical (urban marginalization), social (unemployment, exclusion and stigmatization), politics (exclusion as political actors, strong feeling of denial of recognition).

\section{A DIVERSIFIED GROUP AND TRUST BUILDING}

The interdisciplinary committee selected a group of detainees on the basis of two main principles: the first principle was to gather various profiles that would involve different trajectories, age groups and crimes committed ${ }^{10}$. The second principle was to avoid a counter-productive effect that would lead detainees to feel that their involvement in the

\footnotetext{
9 Moghaddam F., 2005, "The Staircase to Terrorism; A Psychological Exploration », American Psychologist 60:2: 161-169. Mccauley C. et Moskalenko S., 2008, «Mechanisms of Political Radicalization : Pathways. Toward Terrorism », Terrorism and Political Violence 20.3: 415-433.

10 Although having varied profiles and backgrounds, the participants nevertheless shared certain characteristics. Practically all holding French citizenship, they all were descendant from immigrant families, they were all Muslims, but only a part of them were actually practicing. Generally very young, almost all inmates came from disadvantaged neighborhoods of major French cities, where most have followed the "classic" career path, described in particular by Farahd Khosrokhavar (2014), which goes from delinquency to detention, then from the re-Islamization to radicalization. On the other hand, only a quarter of the detainees were in prison for terrorism-related offenses, while the others were imprisoned for other offenses, while at the same time displaying strong signs of radicalisation.
} 
programme was an additional source of stigmatisation. Each inmate was invited during an interview to participate in a programme called "civic commitments" which deals with issues related to their life in prison, challenges they face in society, violence and the difficulties related to the reintegration of prisoners in the social space. As the programme was run on a voluntary basis, different trust-building tools were used. First, each inmate was invited to contribute to the programme by way of mentioning themes to be discussed and people to be invited. Such an approach relied on the idea that the programme had to appeal to the participants and that the inmate should ultimately consider himself as an actor of his detention rather than a simple user. Second, the programme was conceived as a forum for free speech where no counter-narrative would be offered or imposed. This aspect was greatly appreciated by inmates, who "discovered" an unusual and unexpected space of expression that allowed them to gradually enjoy the benefits of exchange and dialogue. At the same time, participants were asked to sign an agreement listing what was allowed and forbidden during the course of the programme (participants had to agree to respect other people's opinions, as well as the facilitators' role, and to participate from the beginning to the end of the programme). This was an additional step taken to foster a process of empowerment and accountability among detainees. Third, anonymity was safeguarded to guarantee and protect freedom of expression. The exception or limitation to this was that any expression of intent to commit violence was not covered by this guarantee. Fourth, participants were from the onset informed as to the aims and the operating methods of the programme. This gave them an awareness as to what they should expect and strengthened mutual legitimacy and trust building.

\section{A THREE-PHASE PROGRAMME}

Twelve inmates were part of the "engagements citoyens programme for two months. Individual follow-ups alternated with collective sessions and involved a wide variety of actors from inside and outside the prison. The programme relied on a process-based approach made up of three phases, with the ultimate objective of encouraging personal empowerment and accountability through evolutionary steps. The first phase aimed to build trust with participants and act on their feelings of stigmatisation. This initial phase involved a theatre workshop to create a group dynamics and facilitate exchanges between all participants. It also included personal interviews to improve mutual 
knowledge of facilitators and detainees and establish a closer relationship between both. Two group collective sessions took place, with the first session focused on detainees' life in prison (interactions with wardens, prison management officers and staff in charge of evaluating prisoners in view of their reintegration in society). During this first collective session inmates were free to talk about difficulties of their lives in jail and express grievances related to their detention, However, they also listened to the points of view of prison staff members who are usually regarded by inmates as nothing more than repressive agents of the state. The second collective session tackled issues associated with life within a society. External actors, particularly active in social activities and political life, were invited to describe their fight against perceived and/or real injustices through means other than violence. During this second session participants were able to talk about important problems that were closely related to their life, which are often left out of the public debate such as discrimination of all kinds, life in the French banlieues, police violence, exclusion, etc. In order to ease exchanges, favour trust building and "re-humanize" participants, each speaker, as well as inmate and facilitator, was asked to describe his/her work or involvement in the society in personal terms. The aim of this first phase was to trigger a process of destigmatization. This is partly done through involving external actors (guards, professors, imams, social workers, etc.), who, through their own narratives shared at collective sessions with inmates, show how civic commitment could play an important role in self-actualization, allowing the inmates in their own turn to express their representations of life in society. Once a minimum level of trust was established and voices were "liberated", the second phase of the programme was to help participants realize how complex some issues may be. Detainees' speech was also re-elaborated by leading prisoners to compare their own situations with others'. This phase, which may be called "opening to otherness" and in some cases "re-humanisation of otherness", involved a high number of collective sessions pertaining to different social and political topics that were considered to be relevant to young inmates such as social and political exclusion, Islamophobia and racism, armed conflicts, ISIS and the Syrian civil war. Detainees were encouraged to confront and discuss different external actors such as politicians, former inmates, scholars, religious leaders, victims of physical violence and terrorism.

During the second phase, and more generally during the entire programme, inmates were not provided with counter-narratives. No actor in the process made any attempt to 
convince them that they were wrong in their interpretations (of faith, for example), based on the idea that inmates themselves have to question their own certitude though dialogue et confrontation. The words of the prisoners were taken seriously. ${ }^{11}$ As a matter of fact, the overarching goals were to enable detainees 1) to talk to people having different perspectives and 2) to coach them in view of the last phase of the programme during which they were asked to talk about themselves and describe personal hardship related to their backgrounds, identities, relationships with families and professional projects. During this last phase, each participant was invited to portray his own journey, in terms of family history, relationships with others, school and professional experiences, and also in terms of expectations and fears. Young people who were losing their connection with society, or who were already imbued with extreme ideas, were thereby encouraged to question their personal experiences, in addition to their perception of society and their relationship to violence. At the core of this last phase were the development of self-reflection and the promotion of different ways to challenge social norms or express personal and collective rage. Or, in other words, how to build pathways toward a citizenship based in commitment and selfreflection.

The programme ended with collective and individual assessments. First, with the help of the theatre actor (or facilitator) who had been involved in the theatre workshop implemented during the first phase of the programme, participants are asked to formulate a collective and overall assessment. Participants were thus put in a position where they could think and evaluate changes within the group as a whole, but also express their collective judgment of the programme to which they participated during two months. Second, personal interviews allowed each participant to assess the personal transformation he experienced during the programme and examine, with the help of the facilitators, how he could further extend this evolution. An ultimate exchange with facilitators, prison management and staff gave participants the opportunity to express their thoughts, opinions on the programme and, more importantly, the feeling that they were finally valued by the penitentiary institutions.

\footnotetext{
${ }^{11}$ An useful type of counter-narratives did emerge, step by step, from this process. This emerged from the differences between inmates' points of view. They ended up discovering that they did not necessarily agree. Their certitude was just apparent. The rational confrontation that had been engineered ended up making them recognize the complexity of the reality.
} 


\section{Tangible results?}

Throughout the programme, a key evolution took place at the individual and collective levels. While the first sessions were hallmarked by verbal abuse and negative behaviours, these features gradually decreased and eventually disappeared as the programme progressed. During the last phase, Manichaean views commonly held by prisoners (often filled with victimisation and conspiracy theories) were gradually replaced by introspection on political-religious commitment and/or practices through considerations on individual trajectories and the meaning of commitment. Three distinct processes, adapted to each profile, made such an evolution of speech and behaviour possible.

The first process can best be described as the reintroduction of doubt to the prisoners' beliefs. The majority of participants were young people with no prior religious knowledge or who were never been involved in political activism. Introspection allowed them to move away from their binary vision of the world, conspiracy fantasies, "everything-or-nothing" and preconceived answers to the problems they were facing in their lives. Thanks to the exchanges with a wide array of external participants and a progressive work upon themselves, their trajectory, their traumas, their expectations, these young people, who a short time earlier had been filled with absolute certainty as to the validity of their own beliefs, full of certainties reconnected with reality, its complexity and the diversity of possible answers to life problems.

The second process reflects a gradual "subjectivation"12 that was achieved though drawing a distinction between the individual/subjective and the collective. The study found that disconnection with society and the use of hate speech take the form of a narrative in which subjective, political and religious explanations overlap or even merge. For most participants, the identification of their "excluded and rejected" self to an Islam that is "attacked all over the world" and to Muslims who are "stigmatized and prevented from living according to their religion" or "suffer under the bombs", is the main argument on which victimisation is based. In many cases, these young people "politicize" the traumas that had an impact on their lives by projecting themselves to the political-religious field. For participants with this kind of profile (the majority), the

\footnotetext{
${ }^{12}$ Michel Wieviorka thus describes the affirmation of the subject (individual or collective): the one who "wants to be recognized, respected, to control his experience, to make his own choices, to build his existence by building himself" (Wieviorka Michel, "L’intégration: un concept en difficulté», Cahiers internationaux de sociologie, 125 (2), 2008: 229).
} 
identification of their individual selves with a group seen as oppressed helps them to avoid facing the reasons for their personal difficulties. The status of victim becomes the main explanatory justification for their own failures, which allows them to escape their responsibilities and to escape from a disappointing condition marked by discrimination, exclusion and lack of perspectives. The process of subjectivation has precisely consisted in their gradual disjunction, that means in an autonomization of the Self in relation to the Us. In this process, the questioning of individual trajectories gradually replaced the certainties of a collective rhetoric built around victimization and conspiracy.

Last but not least, the third process resulted in the mutual legitimation of prisoners and prison staff through the importance granted to inmates' words. As freedom of speech was secured and no counter-narrative was imposed, the participants greatly appreciated this unusual and unexpected space for dialogue where talking and exchanging points of view benefitted them. This proved to be especially true for detainees that had a higher level of religious and political education. Discussing with prison staff various topics such as life in jail, the relationship between inmates and wardens as well as respect for Muslim religious practices led these prisoners to gradually favour less confrontational behaviours, and more openness to rational comparisons that were previously considered to be unnecessary and ineffective.

The key limitations of this action research project should also be discussed. First, the restricted number of people involved and the relative homogeneity of their profiles $^{13}$ make it difficult to expand the results to the overall phenomenon of radicalisation. Radicalisation is a spectrum that sees within a wide variety of profiles and backgrounds - these are themselves the product of psychological, political, religious and social factors. ${ }^{14}$ The outlines in this paper may not necessarily work with all profiles. Second, one has to note the difficulty of ensuring continuity to this process of re-introduction of individual and collective introspection, and thus openness to otherness. As a matter of fact, the programme gave these young people the possibility to think about themselves in "another way" in comparison with what their status of

\footnotetext{
${ }^{13}$ The group was composed by young people with different background, but its relative homogenity comes from the fact that in the group there were no converts, nor women and practcally nor middle-class youth, almost of them coming from French banlieues.

${ }_{14}$ Doosje, B., Loseman, A., Van Den Bos K., 2013, « Determinants of radicalization of Islamic youth in The Netherlands: Personal uncertainty, perceived injustice, and perceived group threat », Journal of Social Issues, 69: 586- 604.
} 
detainees, victims, marginalised or excluded holds for them. However, steps forward were hampered by stiff resistance, in particular because individuals feared a change that was desired yet seen as uncertain, even impossible, within the framework of prison or life in society. In other words, subjective change can be "wiped out" by political and social conditions that may be the source for further rage or even hate towards a society that continues to stigmatize, exclude and marginalized them.

\section{Words as a Tool to Check, Disarm or Fight Radicalization}

The evaluation process, lengthy interviews, the programme itself revealed the deepseated need of young prisoners to verbalize their feelings of injustice, exclusion and anger. The inability to do so is generally one of the main reasons explaining their disengagement from society and their adherence to a radical discourse or violent attitudes. The inmates' words turned out to be the starting point both to detect a radicalisation process and begin a process of rehabilitation. In fact, the relationship based on verbal exchanges proved to be not only a common thread to see if an individual was radicalised or in the process of radicalisation, but also a way to prevent radicalisation and open a space for dialogue. It is precisely the lack of dialogue between the institution and the prisoners that reinforces the feeling of injustice for certain inmates, as some of them may feel discriminated against up to the point of reaching a "paranoid" attitude that lead them to think they are victims of a conspiracy. The action research showed that hate or "anti-institutional" speeches alone are not enough to identify an extremist. However, such elements become an indicator of violent radicalisation when a person shows other signs of crisis such as antecedents of violence, isolation or inward-looking behaviours, a violent attitude in prison, a life marked by traumas, an obsessive feeling of injustice, psychological problems, a sense of individual and/or collective persecution, a sudden change in religious habits and interpersonal relationships. The process of establishing a relationship of exchange and dialogue with each inmate emerged as a way to assess how signs of crisis combine and what solutions should address the vulnerabilities or fragilities in the inmates own personal make-up. As a consequence, identifying the factors that shape the process of radicalisation of each person appears to be a prerequisite to assess the levels of radicalisation, and to distinguish between people who can embark on a rehabilitation programme and those who are "too radicalised" to do so. Spotting such factors is also 
important as it allows practitioners to adapt their response to the different profiles involved, and especially to be cognisant of the vulnerabilities or fragilities of inmates.

\section{CONCLUSION: THE RECOMMITMENT}

The experimental programme led in two French prisons was built on the idea that freedom of speech on topics detainees were interested in could trigger a reflection of detainees about themselves, their personal trajectories and the relation towards others, including family. This would be at the same time a reflection on the meaning of commitment, the modalities of active citizenship, the relation to otherness and the question of violence and its legitimacy.

Central to this approach is the concept of commitment which is a pillar of the notion of citizenship. The latter should be understood as the acceptance of subjective and collective involvement in the construction of the public space, open debate and society. Commitment is thus the centre piece of being a citizen. As a result, the objective of this approach is not deradicalisation or disengagement, meaning changing the person's vision and leading him to relinquish violence, but "re-commitment". The key idea is to work on both individual trajectories and society life to formulate new modalities of citizenship involvement that would limit violence as much as possible, or even exclude it. Contrary to the notions of deradicalisation and disengagement, the individual is seen as an actor that has to express his ideas, act, involve and commit himself. The notion of re-commitment aims at reworking the modalities of political action: the legitimacy of commitment is not challenged, but the modalities of expression of commitment through violence and denial of the other are. We offer young people who do not find in citizenship their means of involvement, people who turn to other forms of commitment that are illegal and illegitimate because they are violent and they deny the existence of others, an alternative way to get committed. The idea is not for them to relinquish their feeling of injustice or justice, but to ponder over finding other modalities of expression and involvement that can contribute to self-achievement. As a matter of fact, this process of individual and collective introspection, the abandonment of ideological certainty and the creation of a space for uncertainty, sets 
the stage for the critical (but fragile) next stage in the journey out of the radicalised mindset - of thinking about oneself differently. ${ }^{15}$

\footnotetext{
${ }^{15}$ The writer would like to express his thanks to Romain Quivooij (Associate Research Fellow, Center of Excellence for National Security at the S.Rajaratnam School of International Studies, Singapore), for his assistance in the translation of this article into English.
} 